Mini-review

\title{
Management of patients with neuromuscular disorders and acute respiratory failure
}

\author{
Caterina Antonaglia ${ }^{1}$ \\ Giancarlo Garuti² \\ Chiara Torregiani ${ }^{1}$
}

\author{
1 S.C. of Pneumology, University Hospital of Cattinara, \\ Trieste, Italy \\ 2 U.O. of Pneumology, "Ospedale Civile Sant’Agostino \\ Estense", Modena, Italy
}

\author{
Address for correspondence: \\ Caterina Antonaglia, MD \\ S.C. of Pneumology \\ Hospital of Cattinara \\ Strada di Flume 447 \\ 34149 Trieste, Italy \\ E-mail: caterinaantonaglia@gmail.com
}

\section{Summary}

Acute respiratory failure (ARF) is a common cause of morbidity and mortality in most advanced neuromuscular disorders (NMD). Deterioration of lung function during NMD may have different severity and time course. During slowly progressive neuromuscular disease an acute event can precipitate the respiratory failure, while rapidly progressive NMD may present as ARF at the onset of the disease. During ARF a patient with NMD may be affected by inspiratory muscles weakness responsible for decreased ventilation, expiratory muscles weakness responsible for altered coughing effectiveness, and bulbar involvement responsible for altered swallowing and airway protection. Neuromuscular disorders may also affect central control of breathing, sleep disorder, bones and joints deformities with consequent ventilatory dysfunction. Usually ARF in NMD is prompted by precipitating factors such as upper airways infections, pneumonia, atelectasis etc. It is important to distinguish respiratory failure due to an acute event or to a rapidly progression of underlying conditions to properly allocate the patient in the more appropriate setting of care. Generally, excessive invasiveness of care must be avoided, and a pro-active early rehabilitation program may help early recovery and minimize complications. Mechanical non invasive positive pressure ventilation (NIPPV) combined with mechanically assisted coughing (MAC) has been established as the standard treatment of severe ARF in NMD. Superiority of NIPPV vs invasive mechanical ventilation (MV) was showed in term of lower mortality, treatment failure, duration of ICU in several studies. Home mechanical noninvasive ventilation and MAC may result dramatic reduction in the need for hospitalization and a prolongation of life expectancy of these patients. To avoid the progression of respiratory failure an early identification of respiratory deterioration is needed, as such as prevention of acute episodes. So, especially in the progressive diseases, is very important to monitor respiratory status with periodic lung function tests. Any respiratory tract infection in neuromuscular disease could trigger acute respiratory failure so it is mandatory take any aggressive measures to prevent and treat this complication. Some of principal preventive measures include vaccination against Pneumococcus $\mathrm{Pn}$. and influenza virus, early antibiotic treatment when bacterial infection is suspected, chest physiotherapy for removal airway secretions or mechanical assisted maneuvers to increase cough efficiency. In conclusion, a proactive, preventive approach is the key for optimal management acute respiratory problems in neuromuscular disorders.

KEY WORDS: acute respiratory failure; neuromuscular disorders; noninvasive ventilation; mechanically assisted coughing; intensive care unit.

\section{Introduction}

Acute respiratory failure (ARF) may be a life-threatening event during the course of several neuromuscular disorders (NMD). It can be the first manifestation of respiratory involvement or most frequently a worsening episode during chronic respiratory impairment. Deterioration of
Acute respiratory failure may be a lifethreatening event in the course of several neuromuscular disorders. lung function during NMD varies in term of severity and time course according to different diseases. However, some general issues for the management of ARF in NMD should be kept in mind by the physicians to reduce time to recovery and to minimize the risks for the patient.

Neuromuscular disorders affecting respiratory function

Neuromuscular disorders are numerous and represent a group of disease involving the muscle, the nerve or the neuromuscular junction (Table 1). The involvement 
Table 1 - Neuromuscular disease affecting respiratory function.

\section{Neuropathic disease}

- Motor neuron disease (Amyotrophic lateral sclerosis, Poliomyelitis, Spinal Muscular atrophy)

- Peripheral neuropathies (Guillain Barrè syndrome, Critical Illness polyneuropathy, Charcot- Marie- Tooth disease)

\section{Disorders of the neuromuscular junction}

- Myasthenia Gravis, Congenital myastenic syndrome, Lambert Eaton, Botulism, etc.

Myopathies

- Acquired myopaties (Polymyositis, Dermatomyositis, Critical illness myopathy)

- Inherited myopathy

- Progressive muscular dystrophy (Duchenne, Becker, Fascioscapulohumeral muscular dystrophy, Myotonic dystrophy)

- Congenital muscular dystrophy (Ullrich congenital muscular distrophy, Emery-Dreifuss muscular dystrophy, etc.)

- Methabolic Myopaties (mitocondrial myopaty, glicogen storage disease type 2)

of respiratory system during the course of a NMD is frequent, but either its severity and onset timing may vary among the different disorders (1). In fact, the onset of disease can be acute [e.g. Guillain-Barré syndrome (GBS)], chronic and relapsing [Multiple Sclerosis (MS), Myastenia gravis (MG)], or slowly progressive (Amyotrophic Lateral Sclerosis- ALS). Some NMD (e.g. GBS or MG) experience respiratory failure with acute onset, and it can be the sole onset of the disease. Nevertheless, the respiratory worsening can be potentially reversible in several cases if properly managed. So we can state that in the rapidly onset neuromuscular diseases (MG , GBS etc.), the principal cause of ARF is the acute weakness of the respiratory muscles. In the slowly progressive neuromuscular disease (e.g. ALS and DMD) respiratory failure can be precipitated by an acute event causing an imbalance between the respiratory load and muscle strength. In spinal muscular atrophy (SMA) type 1 all children develop respiratory failure by the age of 2 years while around $40 \%$ of those with SMA type 2 develop it in childhood. In Duchenne muscular dystrophy respiratory failure tends to follow loss of ambulation and $70 \%$ of patients with Ullrich congenital muscular dystrophy develops respiratory failure during the adolescence. Other conditions related to respiratory failure with very early onset include those with $\mathrm{X}$-linked myotubular myopathy and those with SMARD (SMA with respiratory distress) (2). Otherwise, in Pompe disease respiratory involvement can be one of the first clinical manifestations of the disease, and patients may present respiratory impairment despite still ambulating (3). In other myopathies, such as other muscular dystrophy, fascio-scapulo-humeral muscolar distrophy, limb-girdle muscolar distrophy and myotonic dystrophy the patients experience a progressive re-

duction in muscular respiratory function, with relatively slow progression towards chronic respiratory failure.

\section{Pathophysiology of ventilatory failure in NMD}

Mechanisms of ARF in NMD are based on pathophysiological alterations directly or indirectly involving the respiratory system: muscular weakness, altered control of breathing, sleep respiratory disorders, rib cage deformity, and so on.

\section{Muscular Weakness}

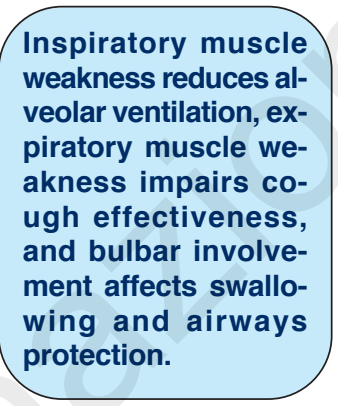

The respiratory system is composed by the inspiratory muscles (diaphragm, external intercostal, scalene, sternocleidomastoid and trapezium) responsible for ventilation, the expiratory muscles (internal intercostal and abdominal muscles) principal responsible for coughing and the glosso-pharyngeal muscles, responsible for airway protection. In neuromuscular disease, the muscles weakness involves all the respiratory muscles, but mostly the diaphragm and inspiratory muscles (4). Patients with NMD adopt a particular breathing pattern that minimizes inspiratory time and transdiaphragmatic pressure in order to avoid fatigue of the diaphragm, generating small tidal volumes and compensatory increase of respiratory rate (5). Compensatory tachypnea with small tidal volumes may cause lung atelectasis with a consequent reduction of the compliance of the respiratory system and increase the mechanical load on already weakened respiratory muscles (6). The final result is alveolar hypoventilation with increased partial arterial pressure of carbon dioxide $\left(\mathrm{PaCO}_{2}\right)(7)$. These mechanisms are the main responsible for hypoxemic and hypercapnic respiratory failure during NMD (8). Another contribution to inspiratory weakness is due to weakness of pharyngeal dilator muscles decreasing upper airway caliber and increasing airway resistance during inspiratory breathing. The latter mechanism imposes a higher mechanical load on inspiratory muscles, especially in Duchenne disease, motor neuron disease and Myasthenia gravis.

The main causes of restrictive disorder in neuromuscular disease are related to chest wall deformities and increased lung elastic recoil. Mechanisms underlying the alterations of respiratory system mechanics are different and multifactorial:

- decreased amplitude of respiratory excursions that cause an ankylosis of costosternal and costovertebral joints

- microatelectasis caused from lack of spontaneous deep breaths, de-recruitment of alveolar units, inefficient cough, inefficient clearance of secretions, impaired activity of surfactant (9).

Expiratory muscles have a minor contribution to respi- 
ratory weakness and ventilatory failure: one study demonstrates that decreased maximal expiratory pressure (MEP) is not an independent predictor of hypercapnia, but it is correlated to ineffective cough (10). The lowest value of MEP related to effective cough is around $50-60 \mathrm{cmH}_{2} \mathrm{O}$. (10) Nevertheless expiratory muscle weakness is essential for cough mechanism. Actually, effective cough requires fully deep inspiration followed by glottis closure and adequate expiratory muscle strength to generate enough intrathoracic pressure to obtain high peak expiratory flows (PCF). Cough ineffectiveness causes bronchial congestion leading to pulmonary infection (11).

\section{Central control of breathing defects}

The central control of breathing is impaired in some NMD, such as Myotonic dystrophy, with an out of proportion retention of $\mathrm{CO}_{2}$ with regard the degree of respiratory involvement, suggesting that central respiratory drive is abnormally reduced. Also there is a reduction in ventilatory response to hypercapnia (12). Patients with chronic nocturnal hypoventilation develop reduced central sensitivity to $\mathrm{CO}_{2}$ because of the retention of bicarbonates in order to compensate the chronic retention of $\mathrm{CO}_{2}$, resetting the central setpoint to $\mathrm{CO}_{2}$ (13).

\section{Sleep disorders}

Sleep related hypoventilation and obstructive sleep apnea are favoured by:

- decreasing in upper airway motor tone during sleep (especially REM sleep)

- pharyngeal dilator muscle weakness (14-16)

- coexisting facial growth abnormalities such as maxillary hypoplasia, macroglossia that can worsen pharyngeal hypotonia.

Usually sleep disorders are common when CV is less than $40 \%$ of predicted and occur during deep sleep (REM) due to muscle hypotonia. In some neuromuscular diseases sleep disorders can occur even if VC is normal: for example in Steinert disease, DMD (17).

\section{Other contributing factors to respiratory impair- ment in NMD}

There are also other factors contributing to respiratory involvement in NMD (18) such as:

- left ventricular pump failure: in some neuromuscular disease, it may cause decreased pulmonary compliance and therefore increased work of breathing or ventilatory perfusion mismatch and abnormal gas exchange (19)

- poor nutrition: it may cause atrophy of diaphragm (20)

- obesity due to poor dietary habits, sedentary status, medications that can facilitate hypoventilation and obstructive sleep apnea (21)

- swallowing problems and gastro-esophageal reflux are frequent and increase bronchial congestion particularly during the night (22)

- orthopedic deformities, especially kyphoscoliosis (23)

- in congenital neuromuscular diseases lung devel- opment is reduced: indeed while in normal subject the alveolar number increases rapidly from birth to 4 years of age, in congenital disease there is a delay of this boost that contributes to respiratory failure (24).

\section{Factors precipitating acute respiratory worsening}

Usually ARF in NMD is prompted by precipitating factors to be identified to treat effectively the acute exacerbation. The most frequent precipitating causes of acute exacerbations in NMD are upper respiratory tract infections or acute
The most frequent precipitating causes of ARF in NMD are infections, pneumonia, aspiration, and surgery. bronchitis $(25,26)$, pneumonia, atelectasis (27), aspiration and bronchospasm. One of the most common precipitating factor is the postoperative condition. This is the case of either thoracic and abdominal surgery, but also every intervention requiring general anesthesia may worsening respiratory conditions in NMD. In myopathies, an associated cardiac dysfunction such as dilated cardiomyopathy, may lead to alteration of the conduction system and to acute heart failure. Less common but severe complications are pneumothorax during MV, pulmonary embolism due to venous stasis in a sedentary habitus, tracheal haemorrage in patients with tracheostomy, acute gastric distention due to non invasive ventilation, and the abuse of sedative drugs (Table 2).

Table 2 - Factors precipitating respiratory failure in NMDs.

Infections/inflammation of respiratory airways

- Upper respiratory tracts infections/acute bronchitis

- Pneumonia

- Atelectasis

\section{Non infective/inflammatory factors}

- Cardiac failure (particularly in patients with myopathies)

- Abuse of sedative drugs

- Aspiration

- Pneumothorax

- Pulmonary embolism

- Tracheal hemorrage (patients with tracheostomy)

- Acute gastric distension due to non invasive ventilation

\section{What to do for patients with NMD and ARF}

In a patient with NMD and ARF there are two principal issues to be addressed:

- identify and remove the cause of respiratory failure

- manage the acute respiratory failure properly.

First it is necessary understand if the exacerbation is
Properly treat the precipitating cause of ARF and give respiratory care as needed. 


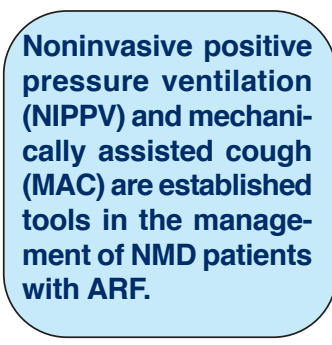

due to an acute event, or to the acute progression of underlying conditions. Sometimes, ARF in NMD may also be linked to bulbar involvement with impaired swallowing an aspiration. To identify the cause of respiratory failure is necessary to rule out the use of sedative and hypnotic drugs, to investigate the onset and progression of the disease. Usually, the following checks are useful: common blood tests, sputum analysis, electrocardiogram to rule out arrhytmias, chests $X$ ray to investigate the presence of either cardiomegaly, pulmonary congestion or pneumonia. CT scan may help if pneumothorax is suspected. Echocardiogram is useful in case of probable or suspected heart failure. Respiratory tract infections are the most common cause of hospital admission and death in NMD patients with respiratory muscle involvement. When a patient with neuromuscular disease has an acute infection, several issues should be considered:

1) the severity of the underlying disease

2) signs of respiratory distress

3) somnolence

4) decreased appetite

5) retractions

6) tachycardia and tachypnea

7) oxygen saturation lower than baseline or under $94 \%(16)$.

Management of an ARF episode in NMD implies both treatment of precipitating causes and supportive therapy for the insufficient respiratory function. Mechanical noninvasive positive pressure ventilation (NIPPV) combined to me-
A dedicated respiratory intermediate care unit (RICU) may be the optimal care setting for NMD patients with ARF. chanically assisted coughing have been established as first line treatment for severe ARF in $\operatorname{NMD}(28,29)$. As suggested by the Spanish guidelines (30) NIPPV is mandatory in NMD patients with acute respiratory acidosis, while intubation and invasive ventilation must be considerate only when a noninvasive approach is contraindicated or ineffective (30). NIPPV is contraindicated in patients with severe inability to swallow, uncontrollable airway secretions despite use of aids, severe hypoxemia, severe impaired mental status, hemodynamic instability, recent facial upper airway or abdominal surgery or bowel obstruction (31-34) (Table 3). NIPPV failure is defined as the inability to: reduce dyspnea or lethargy, decrease the respiratory rate, improve blood gas exchange (arterial $\mathrm{PH}<7: 30$ or below the value on admission), maintain $\mathrm{PaO} 2>65 \mathrm{mmHg}$ with a $\mathrm{FiO} 2>0.6$ within 6-12 hours of application, despite optimal ventilatory setting (35). NIPPV represents an effective life support treatment in NMD with ARF. An open study including 17 patients with NMD found NIV effective in avoiding tracheal intubation in $79 \%$ out of the paT-
Table 3 - NIPPV contraindications.

- inability to swallow
- uncontrollable airway secretions despite use of aids
- severe hipoxemia
- hemodinamic instability
- recent facial upper airway or abdominal surgery
bowel obstruction

tients (36). A randomized controlled trial (37) of early application of NIV in patients with ARF and NMD showed that NIV statistically reduce the rate of tracheal intubation in comparison with the usual medical care alone (Figure 1).

If the patient is already on home NPPV at the time of the acute illness, it should be requested a re-evaluation of the ventilator settings. In some cases it could be necessary using NIV more intensively, increasing inspiratory pressure support or IPAP by steps of 2-5 $\mathrm{cmH}_{2} \mathrm{O}$ according to $\mathrm{pCO}_{2}$ levels, and eventually adding supplement of oxygen therapy to NIV to maintain $\mathrm{SATO}_{2}>93 \%$. The set ventilator expiratory pressures or EPAP should not exceed a maximum of 7 $\mathrm{cmH}_{2} \mathrm{O}$. When the patient is completely $24 / \mathrm{hrs}$ NIV dependent, it could be useful to alternate different types of mask (38) and add humidification. We suggest to check constantly the need of mechanically assisted coughing in case of bronchial secretions' retention, and the administration of bronchodilators if wheezing is detected (39).

Another important issue during an ARF episode in patients with NMD is the identification of the more appropriate care-setting. The decision to admit the patient to a hospital or to manage him/her at home is crucial. It's important to note that not always the most intensive and invasive setting is the safest location to manage NMD patients with ARF. Some authors (40-43) report dramatic reduction of hospitalizations and a prolongation of life expectancy linked to regular home management of ARF episodes, but well designed controlled studies are lacking. A well organized telemonitored hospital at home setting may provide a safe management of mild ARF episodes for NMD patients (42) and a mechanical removal of secretion with insufflator-exsufflator. However, when NIPPV support is needed for 24 hours a day together with continuous clinical and instrumental monitoring (e.g. not only pulse-oxymetry) and removing of bronchial secretion by bronchoscopy mean a dedicated respiratory highdependency care unit or respiratory intermediate care unit (RICU) may be the optimal care setting for NMD patients with ARF (32). An early and preventive increased utilization of NIPPV at home or in critical setting may avoid sedation and complications linked to invasive MV (40-43). Superiority of NIPPV vs invasive MV is demonstrated in term of lower mortality, treatment failure, duration of ICU in different study (32, 44). If a patient with neuromuscular disease undergoes intubation a big issue to be solved is the timing 


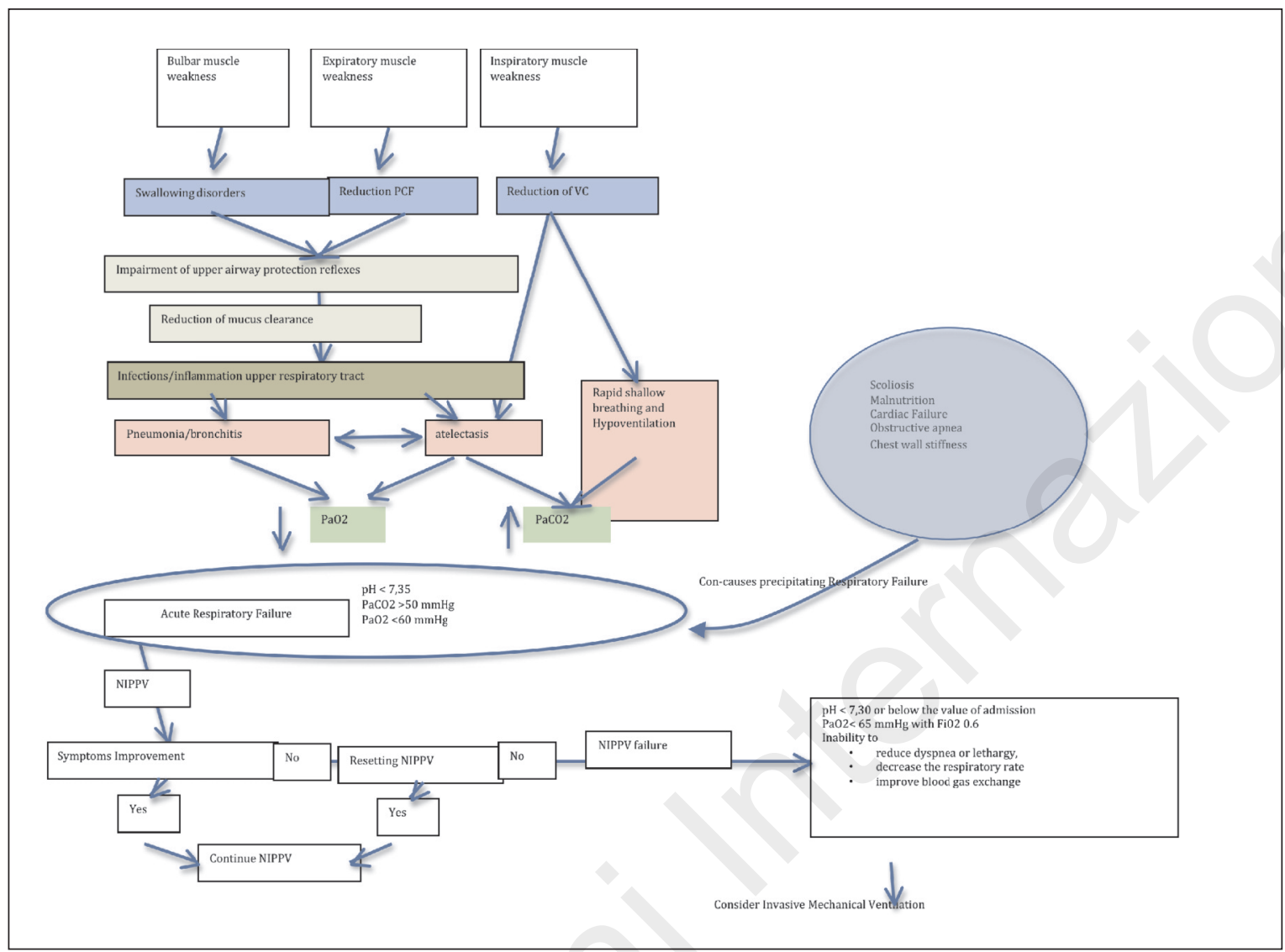

Figure 1 - Flow chart on management of ARF in NMDs.

of extubation and difficult weaning. Recommendations for optimal timing of weaning in NMD patients suggest to extubate when the patient is stable, arterial oxygen saturation on room air normalized and the causes leading to respiratory failure solved and properly treated. Moreover, extubation of NMD patients should be done with an adequate cough reflex, minimally reduced secretions, and lower MV pressures tolerated for a prolonged period of time without any sign of respiratory fatigue (45). There is general agreement that, if not contraindicated (e.g., severe bulbar impairment), patients with slowly progressive NMD should be extubated directly to NIPPV combined with assisted coughing (46). Extubation failure is relatively common in patients with MG (44\% of extubation attempts), and the presence of atelectasis is the strongest predictor of this complication (47-49). Aggressive airway clearance is another key point to manage ARF in NMD. There are different techniques of airway clearance that include manual assisted coughing, mechanical insufflator-exsufflator devices, manual chest percussion, air-stacking techniques, and postural drainage. The role of airway secretion management by physiotherapist, either done manually or with insufflation-exsufflation, is now established (50). Mechanical insufflation-exsufflation significantly reduces treatment failure in patients with neuromuscular disease and respiratory tract infection, compared to historical controls conventionally managed with chest physiotherapy alone (51).

What to avoid in patients with neuromuscular disorders

Since symptoms of respiratory failure are not obvious and may be confused with muscular weakness, especially in the presence of otherwise stable muscular function and maintained ambulation, respiratory involvement must be systematically investigated either clinically and functionally. To avoid the progression of

Invasiveness, immobility, sedative and paralyzing drugs should be avoided or strongly limited during ARF in NMD patients. respiratory failure is necessary to identify early signs of impending respiratory failure and to prevent acute events that may be precipitated by infections, drugs, and co-morbidities.

\section{Do not misunderstand progression of respiratory} involvement

It is very important to assess respiratory status regularly by means of periodic lung function tests to predict the progression of disease. A difference in forced vital 
capacity (predicted percent FVC) between seated and in supine position $>20 \%$ indicates diaphragmatic weakness and it is a valid

We suggest an early
aggressive rehabili-
tation program to mi-
nimize complications
and accelerate reco-
very.
predictor of nocturnal hypoventilation (52, 53). When FVC is less than $60 \%$ predicted, then sleep breathing disorder are very common in NMD patients. For example, a FVC $<40 \%$ may indicate nocturnal hypoventilation and possibly progression to chronic respiratory failure. The respiratory muscle strength must be regularly assessed by either maximal inspiratory pressure (MIP) and maximal expiratory pressure (MEP) (54). Normal values of MIP and MEP are 80$120 \mathrm{~cm} \mathrm{H} \mathrm{H}_{2} \mathrm{O}$. A value of less than $60 \mathrm{~cm} \mathrm{H} \mathrm{H}_{2} \mathrm{O}$ suggests symptomatic respiratory muscle impairment, while when MIP is $20 \mathrm{~cm} \mathrm{H} \mathrm{H}_{2} \mathrm{O}$ or less there is a clear requirement for assisted mechanical ventilation $(55,56)$. If MIP values are lower than MEP ones indicate the presence of diaphragmatic weakness. Peak cough flow, polysomnography, and blood gases are also useful to evaluate the patient $(55,57)$. PEF is the maximum flow obtained during forced expiration, starting from total lung capacity (normal range: 360-1200 $\mathrm{L} / \mathrm{min}$, average value: $580 \mathrm{~L} / \mathrm{min}$ ) indicating the extent to which a patient succeeds in achieving maximum forced expiration independent of glottis function. Otherwise, PCF, is the expiratory flow measured after the compression phase of forced expiration at closed glottis. A peak cough flow assessment may help to estimate the patient's ability to clear secretions. It can be obtained with a simple peak flow meter in collaborative patients. Usually the measurement of PCF is made by mouthpiece and closed nose, but in children or adults with facial weakness a mask may be required to achieve a reliable value. According to some Authors (14), cough assistance is required when unassisted PCF $<160-180 \mathrm{~L} / \mathrm{min}$ (58). Actually, there is a difference between spontaneous unassisted PCF and PCF assisted by air stacking and an abdominal thrust. When patients are acutely and critically ill, mechanically assisted cough or MAC is the most used way to clear airway secretions. If a patient cannot generate $\mathrm{PCF}>270-300 \mathrm{~L} / \mathrm{m}$ with assistance, MAC is needed to prevent respiratory tract complications such as atelectasis and pneumonia leading to ARF (59). It has been shown that PCF $>160 \mathrm{~L} / \mathrm{min}$ is associated with successful extubation or decannulation in patients with neuromuscular diseases (60). For this reason, in the 2009 ACCP (American College of Chest Physicians) guidelines for patients with Duchenne muscular dystrophy indicated that $M A C$ is required when $\mathrm{PCF}<270 \mathrm{~L} / \mathrm{min}$ or $\mathrm{MEP}<60 \mathrm{cmH}_{2} \mathrm{O}$ before anaesthesia for surgery (61).

Polysomnography can detect or confirm sleep breathing disorders and should include end tidal $\mathrm{CO}_{2}$ monitoring or transcutaneous $\mathrm{CO}_{2}$ monitoring. Arterial or capillary blood gases are also used to assess respiratory failure $(52,62,63)$.

\section{Prevent complication due to excessive invasive- ness of care}

Invasive monitoring and mechanical ventilation performed in ICU are very useful tools in life-threatening situations, but can also be harmful for fragile patients like NDM often are. Moreover, sedative and paralyzing drugs should be avoided or strongly limited during ARF in NMD patients. A dedicated hospital setting for NIV and noninvasive monitoring may be more effective and less costly than a traditional ICU for NMD patients. No use of invasive lines and MV allows the NMD patient free to move, speak, cough, eat and drink with less risk for nosocomial infections and pneumonia, less damage to joints and muscles. A particular attention should be paid to avoid critical illness neuro-myopathy during an ARF episode managed in hospital.

\section{Avoid progress of disability linked to an ARF episode}

A prolonged stay in ICU or in hospital without an aggressive rehabilitative attitude by the physician and nurses may be deleterious for NMD patients with limited ambulatory and muscular autonomy before the ARF episode. In fact, a prolonged immobility, sedative drugs, invasive lines and airways may lead to several complications, e.g. deteriorating of the ability of movement, walking, swallowing, and speech. We suggest an aggressive rehabilitation program promptly begun from the first day of ARF in NMD patients hospitalized or not. An early rehabilitation program prevent the consequences of immobility and ARF even in ARDS patients without NMD, but it may be particularly important for NMD patients.

\section{Prevention of acute events}

Any respiratory tract infection in neuromuscular disease is a possible trigger for acute respiratory failure so it is imperative take any measure to prevent and treat these episodes. This includes anti-pneumococcal and influenza vaccination, antibiotic treatment when bacterial infection is suspected, chest physiotherapy for removal of airways secretions and even mechanical assisted maneuvers to increase cough efficiency. Another important way to prevent acute respiratory failure especially in neuromuscular diseases is to use mechanical ventilation at home: several investigation have shown that nocturnal ventilatory support can improve daytime arterial blood gases, as well as quality of life and survival (64-66). The chronic use of home NIPPV may also decrease pulmonary morbidity and hospitalization rates. For this reason is very important that the timing to begin NIPPV is correctly recognized.

A recent consensus conference suggested that NIPPV should be recommended in symptomatic patients with at least one of the following:

- symptomatic daytime hypercapnia with an arterial $\mathrm{PCO}_{2}$ greater than $45 \mathrm{mmHg}$

- symptomatic nocturnal hypoventilation $\left(\mathrm{PCO}_{2}\right.$ of 50 for $50 \%$ of sleep time or nocturnal oxyhemoglo- 
bin saturation less than $88 \%$ for over five consecutive minutes)

- severe underlying pulmonary function abnormalities (MIP $<60 \mathrm{cmH}_{2} \mathrm{O}$ OR fvc $<50 \%$ of predicted).

Other minor indications are: recurrent chest infections (>3 a year) and non-symptomatic nocturnal hypercapnia or hypopneas on an individual basis $(32,67,68)$. Administration of NPPV to NM patients with chronic hypoventilation may be expected to improve physiological function and quality of life as well as to decrease the frequency of episodes requiring acute care. For these reason in recent years NPPV has assumed a central role in the management of NMD patients $(67,69)$. There are conditions in which longterm invasive ventilation is required via tracheostomy: this is the case of recurrent aspiration, severe bulbar involvement, inability to tolerate NPPV, ineffective NPPV, severe retention of secretions not controlled by noninvasive measures, and ventilatory dependency for more than 20 hours a day (70).

\section{Organizative issues}

Since slowly progressive NMDs are characterized by progressive clinical deterioration, these patients must be involved in the decision-making process regarding treatment escalation, such as endotracheal intubation, tracheotomy and eventually the option of palliative care $(71,72)$. Providing patients and their families information about treatment options and anticipating possible future needs are crucial steps to manage properly respiratory issues in NMD patients. Advance discussion of treatment plan should be the standard of care for these patients, especially in patients diagnosed with type 1 SMA, ALS and other NMDs in the advanced stages of the disease, as these patients are the most fragile. When ARF occurs in these patients, special attention must be paid to the regulatory laws in each country and to the complex ethical issue of providing these patients with a permanent artificial airway (irreversible endotracheal intubation). NIPPV is often the only way to maintain life in NMD patients (73). Careful monitoring of symptoms, regular assessment of pulmonary function, appropriate pre-surgical management, and aggressive treatment of respiratory infections must be considered as a standard of care. The key to care of the respiratory issues in neuromuscular disorders is a proactive and preventive approach.

\section{References}

1. Mehta S. Neuromuscular disease causing acute respiratory failure. Respir Care. 2006;51:1016-21.

2. Simonds AK. Chronic hypoventilation and its management. Eur Respir Rev. 2013(129):325-32.

3. Mellies U, Lofaso F. Pompe disease: A neuromuscular disease with respiratory muscle involvement. Respiratory Medicine. 2009;103:477-484.

4. D’Angelo MG, Romei M, Lo Mauro A, Marchi E, Gan- dossini S, Bonato S, Comi GP, Magri F, Turconi AC, Pedotti A, Bresolin N, Aliverti A. Respiratory pattern in an adult population of dystrophic patients. J Neurol Sci. 2011;306(1-2):54-61.

5. Misuri G, Lanini B, Gigliotti F, landelli I, Pizzi A, Bertolini MG, Scano G. Mechanism of $\mathrm{CO}(2)$ retention in patients with neuromuscular disease. Chest. 2000;117(2):447-53.

6. Birnkrant DJ. The assessment and management of the respiratory complications of pediatric neuromuscular diseases. Clin Pediatr (Phila). 2002;41(5):3018.

7. Katz SL, Gaboury I, Keilty K, Banwell B, Vajsar J, Anderson P, Ni A, Maclusky I. Nocturnal hypoventilation: predictors and outcomes in childhood progressive neuromuscular disease. Arch Dis Child. 2010;95 (12):998-1003.

8. Ambrosino N, Carpenè N, Gherardi M. Chronic respiratory care for neuromuscular diseases in adults. Eur Respir J. 2009;34(2):444-51.

9. Marinelli WA, Leatherman JW. Neuromuscular disorders in the intensive care unit. Crit Care Clin. 2002;18(4):915-929.

10. Polkey MI, Lyall RA, Green M, Nigel Leigh P, Moxham $\mathrm{J}$. Expiratory muscle function in amyotrophic lateral sclerosis. Am J Respir Crit Care Med. 1998;158 (3):734-41.

11. Suárez AA, Pessolano FA, Monteiro SG, Ferreyra G, Capria ME, Mesa L, Dubrovsky A, De Vito EL. Peak flow and peak cough flow in the evaluation of expiratory muscle weakness and bulbar impairment in patients with neuromuscular disease. Am J Phys Med Rehabil. 2002;81(7):506-11.

12. Bégin P, Mathieu J, Almirall J, Grassino A. Relationship between chronic hypercapnia and inspiratorymuscle weakness in myotonic dystrophy. Am J Respir Crit Care Med. 1997 Jul;156(1):133-9.

13. Aruj PK, Monteiro SG, De Vito EL. Analysis of factors associated with chronic hypercapnia in patients with myotonic dystrophy. Medicina (B Aires). 2013;73(6): 529-34

14. Khan Y, Heckmatt JZ. Obstructive apnoeas in Duchenne muscular dystrophy. Thorax. 1994;49:15761.

15. Garcia-Pachon E, Marti J, Mayos M, et al. Clinical significance of upper airway dysfunction in motor neuron disease. Thorax. 1994;49:896-900.

16. Putman MT, Wise RA. Myasthenia gravis and upper airway obstruction. Chest. 1996;109:400-4.

17. Hillman D, Singh B, McArdle N, Eastwood P. Relationships between ventilatory impairment, sleep hypoventilation and type 2 respiratory failure. Respirology. 2014;19(8):1106-16.

18. Matecki S, Petrof BJ. Respiratory consequences of neuromuscolar disease. Respiratory Muscles and Control of Breathing. 2005.

19. Krachman SL, Criner GJ, Chatila W. Cor pulmonale and sleep-disordered breathing in patients with restrictive lung disease and neuromuscular disorders. Semin Respir Crit Care Med. 2003;24(3):297-306.

20. Rochester DF. Malnutrition and the respiratory muscles. Clin Chest Med. 1986 Mar;7(1):91-9. 
21. Chebbo A, Tfaili A, Jones SF. Hypoventilation syndromes. Med Clin North Am. 2011;95(6):1189-202.

22. Chaw E, Shem K, Castillo K, Wong SL, Chang J. Dysphagia and Associated Respiratory Considerations in Cervical Spinal Cord Injury. Top Spinal Cord Inj Rehabil. 2012;18(4):291-299.

23. Karol LA. Scoliosis in patients with Duchenne muscular dystrophy Bone Joint Surg Am. 2007;89 Suppl 1:155-62.

24. Gayraud J, Ramonatxo M, Rivier F, Humberclaude V, Petrof B, Matecki S. Ventilatory parameters and maximal respiratory pressure changes with age in Duchenne muscular dystrophy patients. Pediatr Pulmonol. 2010;45(6):552-9.

25. Poponick JM, Jacobs I, Supinski G, Di Marco AF. Effect of upper respiratory tract infection in patients with neuromuscular disease. Am J Respir Crit Care Med. 1997;156:659-64.

26. Bach JR, Rajaraman R, Ballanger F, Tzeng AC, Ishikawa $Y$, Kulessa R, et al. Neuromuscular ventilatory insufficiency: effect of home mechanical ventilator use vs oxygen therapy on pneumonia and hospitalization rates. Am J Phys Med Rehabil. 1998; 77:8-19.

27. Schmidt-Nowara WW, Altman AR. Atelectasis and neuromuscular respiratory failure. Chest. 1984;85: 792-5.

28. Racca F, Del Sorbo L, Mongini T, Vianello A, Ranieri VM. Respiratory management of acute respiratory failure in neuromuscular diseases Minerva Anestesiologica. January 2010.

29. Mellies U, Dohna-Schwake C, Voit T. Respiratory function assessment and intervention in neuromuscular disorders. Curr Opin Neurol. 2005;18(5):543-7.

30. Farrero E, Antón A, Egea CJ, Almaraz MJ, Masa JF, Utrabo I, Calle M, Verea H, Servera E, Jara L, Barrot E, Casolivé V; Sociedad Española de Neumología y Cirugía Torácica (SEPAR). Guidelines for the management of respiratory complications in patients with neuromuscular disease. Sociedad Española de Neumología y Cirugía Torácica (SEPAR). Arch Broncopneumol. 2013;49(7):306-13.

31. Servera E, Sancho J, Zafra MJ, Català A, Vergara $P$, Marín J. Alternatives to endotracheal intubation for patients with neuromuscular diseases. Am J Phys Med Rehabil. 2005;84:851-7.

32. Vianello A, Bevilacqua M, Arcaro G, Gallan F, Serra E. Non-invasive ventilatory approach to treatment of acute respiratory failure in neuromuscular disorders. A comparison with endotracheal intubation. Intensive Care Med. 2000;26:384-90.

33. British Thoracic Society Standards of Care Committee. Non-invasive ventilation in acute respiratory failure. Thorax. 2002;57:192-211.

34. Mehta S, Hill N.S. State of the art: noninvasive ventilation. Am J Respir Crit Care Med. 2001;163:54077.

35. Vianello A, Corrado A, Arcaro G, Gallan F, Ori C, Minuzzo $M$, et al. Mechanical insufflations-exsufflation improves out-comes for neuromuscular disease patients with respiratory tract infections. Am J Phys Med Rehabil. 2005;84:83-8.
36. Servera E, Sancho J, Zafra MJ, Catala A, Vergara P, Marin J. Alternatives to endotracheal intubation for patients with neuromuscular diseases. Am J Phys Med Rehabil. 2005;84(11):851-857.

37. Martin TJ, Hovis JD, Costantino JP, Bierman MI, Donahoe MP, Rogers RM, et al. A randomized, prospective evaluation of noninvasive ventilation for acute respiratory failure. Am J Respir Crit Care Med. 2000;161(3 Pt 1):807- 813.

38. Garuti G, Nicolini A, Grecchi B, Lusuardi M, Winck JC, Bach JR. Open circuit mouthpiece ventilation: Concise clinical review. Rev Port Pneumol. 2014; 20(4):211-8.

39. Simonds AK. NIV and Neuromuscular disease. Eur Respir Mon. 2008;41:224-239.

40. Vicken W, Elleker G, Cosio MG. Detection of upper airway muscle involvement in neuromuscular disorders using the flow-volume loop. Chest. 1986;90:527.

41. Hon AJ, Bach JR. Chronic respiratory care for neuromuscular diseases in adults. Eur Respir J. 2010; 35(5):1192.

42. Garuti G, Bagatti S, Verucchi E, Massobrio M, Spagnolatti L, Vezzani G, Lusuardi M. Pulmonary rehabilitation at home guided by telemonitoring and access to healthcare facilities for respiratory complications in patients with neuromuscular disease. Eur J Phys Rehabil Med. 2013;49(1):51-7.

43. Vitacca M, Paneroni M, Trainini D, Bianchi L, Assoni G, Saleri M, Gilè S, Winck JC, Gonçalves MR. At home and on demand mechanical cough assistance program for patients with amyotrophic lateral sclerosis. Am J Phys Med Rehabil. 2010;89(5):401-6.

44. Rabinstein A, Wijdicks EF. BiPAP in acute respiratory failure due to myasthenic crisis may prevent intubation. Neurology. 2002;59:1647-9.

45. Maclntyre N. Ventilator discontinuation process: evidence and guidelines. Crit Care Med. 2008;36:32930.

46. Sancho J, Servera E. Non-invasive ventilation for patients with neuromuscular disease and acute respiratory failure. Chest. 2008;133(1):314-5.

47. Seneviratne J, Mandrekar J, Wijdicks EF, Rabinstein AA. Predictors of extubation failure in myasthenic crisis. Arch Neurol. 2008;65:929-33.

48. Bach JR, Gonçalves MR, Hamdani I, Winck JC. Extubation of patients with neuromuscular weakness: a new management paradigm. Chest. 2010;137(5): 1033-9.

49. Bach JR. Risk factors for extubation success in patients following failure of a spontaneous breathing trial. Chest. 2007;131(5):1615.

50. Fauroux B, Guillemot N, Aubertin G, Nathan N, Labit $A$, Clement A, et al. Physiologic benefits of mechanical insufflation-exsufflation in children with neuromuscular diseases. Chest. 2008;133(1):161-168.

51. Garuti G, Lusuardi M, Bach JR. Management of cough ineffectiveness in neuromuscular disorders. Shortness of breath. 2013;2(1):28-34.

52. Wallgren-Pettersson C, Bushby K, Mellies U, Simonds A. 117th ENMC workshop: ventilatory support in congenital neuromuscular disorders - congenital 
myopathies, congeni- tal muscular dystrophies, congenital myotonic dystrophy and SMA (II); 2003 April 4-6, Naarden, The Netherlands. Neuromuscul Disord. 2004;14:56-69.

53. Mellies U, Dohna-Schwake C, Voit T. Respiratory function assessment and intervention in neuromuscular disorders. Curr Opin Neurol. 2005;18:543-547.

54. Stefanutti D, Fitting JW. Sniff nasal inspiratory pressure. Reference values in Caucasian children. Am J Respir Crit Care Med. 1999;159:107-111.

55. Cabrera Serrano M, Rabinstein AA. Usefulness of pulmonary function tests and blood gases in acute neuromuscular respiratory failure. European Journal of Neurology. 2012;19:452-456.

56. Gozal D. Pulmonary manifestations of neuromuscular disease with special reference to Duchenne muscular dystrophy and spinal muscle atrophy. Pediatr Pulmonol. 2000;29:141-150.

57. Mellies U, Schultze S, Schwake C. Respiratory muscle function in 300 healthy children. Eur Resp J. 2001;18:P827.

58. Soudon P, Steens M, Toussaint M. Désobstruction trachéo-bronchique chez les patients restrictifs majeurs paralysés. Respir Care. 1999;3(1):3-24.

59. Gomez-Merino E, Bach JR. Duchenne muscular dystrophy: prolongation of life by noninvasive respiratory muscle aids. Am J Phys Med Rehabil. 2002;81(6):411-415.

60. Bach JR, Saporito LR. Criteria for extubation and tracheostomy tube removal for patients with ventilatory failure: a different approach to weaning. Chest. 1996;110:1566-1571.

61. Birnkraut DJ. The American College of Chest Physicians. Consensus Statement on the Respiratory and related Management of patients with Duchenne Muscular Dystrophy undergoing anesthesia or sedation. Pediatrics. 2009;123:s24-s244.

62. Shahrizaila N, Kinnear WJM, Wills AJ. Respiratory involvement in inherited primary muscle conditions. J Neurol Neurosurg Psychiatry. 2006;77:1108-1111.

63. Dohna-Schwake C, Ragette R, Mellies U, et al. Respiratory function in congenital muscular dystrophy and limb-girdle muscular dystrophy. Neurology.
2004;62:513-514

64. Passamano L, Taglia A, Palladino A, Viggiano E, D'Ambrosio P, Scutifero M, Rosaria Cecio M, Torre V, De Luca F, Picillo E, Paciello O, Piluso G, Nigro G, Politano L. Improvement of survival in Duchenne Muscular Dystrophy: retrospective analysis of 835 patients. Acta Myol. 2012;31(2):121-5.

65. Villanova M, Brancalion B, Mehta AD. Duchenne muscular dystrophy: life prolongation by noninvasive ventilatory support. Am J Phys Med Rehabil. 2014 Jul;93(7):595-9.

66. McKim DA, Griller N, LeBlanc C, Woolnough A, King J. Twenty-four hour noninvasive ventilation in Duchenne muscular dystrophy: a safe alternative to tracheostomy. Can Respir J. 2013;20(1):e5-9.

67. Hess D. Noninvasive ventilation in neuromuscular disease: equipment and application. Respir Care. 2006;51:896-912.

68. Tzeng A, Bach J. Prevention of pulmonary morbidity for patients with neuromuscular disease. Chest. 2000;118:1390-1396.

69. Katz S, Selvadurai H, Keilty K, et al. Outcome of noninvasive positive pressure ventilation in paediatric neuromuscular disease. Arch Dis Child. 2004;89:121124.

70. Consensus Conference Clinical indications for noninvasive positive pressure ventilation in chronic respiratory failure due to restrictive lung disease COPD and nocturnal hypoventilation. A Consensus Conference report. Chest. 1996;116(1999):521-534.

71. Mitchell I. Spinal muscular atrophy type 1: what are the ethics and practicality of respiratory support? Paediatr Respir Rev. 2006;7(Suppl 1): S210-1.

72. Galavotti V, Idotta G, Garuti G. Consensus Conference Assistenza Domiciliare Respiratoria: documento di consenso. Rassegna di Patologia dell'Apparato Respiratorio. 2010;25:84-101.

73. Curtis JR, Cook DJ, Sinuff T, White DB, Hill N, Keenan SP, et al. Society of Critical Care Medicine Palliative Noninvasive Positive Ventilation Task Force. Noninvasive positive pressure ventilation in critical and palliative care settings: understanding the goals of therapy. Crit Care Med. 2007;35:932-9. 